Leading article / Uvodnik

\title{
Utrinek časa ob stoletnici poklica medicinske sestre na Slovenskem
}

\author{
A hundred years of the nursing profession in Slovenia
}

\author{
Monika Ažman
}

Gradišek (1970) ob praznovanju petdesetletnice delovanja medicinskih sester zapiše, da je sestra Boškinova pred petdesetimi leti s svojim delom in zgledom prebila led poklicu medicinske sestre pri nas. V obdobju naslednjih petdesetih let se zdi, da je spomin na pionirko poklica na Slovenskem živ kot še nikoli do sedaj. Hkrati pa se zdi, da se nekateri temeljni gradniki stroke tudi $\mathrm{v}$ stotih letih niso premaknili $\mathrm{z}$ mrtve točke.

$\mathrm{V}$ viziji Strategije razvoja zdravstvene nege in oskrbe $v$ sistemu zdravstvenega varstva $v$ Republiki Sloveniji za obdobje od 2011 do 2020 je smelo zapisano, da želimo sodobno, na dokazih temelječo zdravstveno nego in oskrbo, ki bosta osredotočeni na potrebe pacienta, družine in širše družbene skupnosti. Strateška področja razvoja, ki so pomembna za delovanje in razvoj zdravstvene nege in oskrbe, so: izobraževanje, management in vodenje, informatizacija, pravna ureditev in razvoj dejavnosti zdravstvene nege in oskrbe (Strategija razvoja zdravstvene nege in oskrbe $v$ sistemu zdravstvenega varstva v Republiki Sloveniji za obdobje od 2011 do 2020, 2011).

Republika Slovenija se je $\mathrm{z}$ vstopom v Evropsko unijo (EU) zavezala $\mathrm{k}$ spoštovanju direktive EU za regulirane poklice 2005/36/EC (Direktiva Evropskega parlamenta in Sveta 2005/36/, 2005), kjer so opredeljeni minimalni kriteriji za izobraževanje poklicev: zdravnik, zobozdravnik, farmacevt, diplomirana medicinska sestra, diplomirana babica, veterinar, arhitekt. Izobraževanje za poklic medicinska sestra je izobraževanje najmanj na visokošolskem strokovnem programu (VS) zdravstvene nege, ki je usklajeno z direktivo EU (Kadivec, et al., 2013). Ta del strategije se izvaja na osmih visokošolskih zavodih oziroma fakultetah v okviru univerz ali na samostojnih izobraževalnih zavodih na območju celotne države.

Strategija razvoja zdravstvene nege in oskrbe v sistemu $z$ dravstvenega varstva $v$ Republiki Sloveniji za obdobje od 2011 do 2020 (2011) priporoča, da ministrstvo za področje srednjega šolstva vpis $\mathrm{v}$ izobraževanje na srednješolskih strokovnih in poklicnih programih postopoma znižuje. Pri tem naj upošteva v stroki zastavljeno piramido »obračanja» zaposlenih $\mathrm{v}$ zdravstveni negi $\mathrm{v}$ korist diplomiranih medicinskih sester / zdravstvenikov v razmerju $70: 30$. Prav tako je treba v socialnovarstvenih zavodih in drugje postopoma zamenjati bolničarje negovalce za tehnike zdravstvene nege. Zdi se, da je področje zdravstvene nege prav na tem področju najšibkejše in edino, ki dobesedno sledi Resoluciji o nacionalnem planu zdravstvenega varstva 2016-2025 (2016) »Skupaj za družbo zdravja«, ki v posebnem poglavju opredeljuje tudi finančno vzdržnost zdravstvenega sistema. Težko je verjeti, da je zapis leta 2019 skoraj enak zapisu iz leta 1970. Gradišek (1970) navaja, da je bila reforma zdravstvenih šol v šestdesetih letih prejšnjega stoletja nujno potrebna, saj šolanje medicinskih sester ne sme biti statično, temveč se mora prav tako kakor drugo strokovno šolstvo dinamično prilagajati družbeni rasti ter se $\mathrm{z}$ njo vred vzporedno razvijati. Potemtakem bi petdeset let pozneje razumeli, da bi skladno $\mathrm{z}$ razvojem znanosti, tehnologije, medicine, robotike ... sledili tudi razvoju izobraževanja za poklice v zdravstveni negi in bi kot osnovnega sodelavca diplomirani medicinski sestri izobraževali izključno tehnika zdravstvene nege na srednjem strokovnem nivoju. V sistemu zdravstvenega varstva večinski delež še vedno predstavljajo tehniki zdravstvene nege in bolničarji negovalci in ne diplomirane medicinske sestre / zdravstveniki, saj so z vidika zagotavljanja ekonomske vzdržnosti cenejši. Tako vrhnji kot srednji management zdravstvenih in tudi socialnovarstvenih zavodov morata prevzeti odgovornost za ustrezno sestavo negovalnega tima, vezanega na kategorizacijo potreb pacientov po zdravstveni negi. Da bi to znali in zmogli, morajo imeti sodobni managerji $\mathrm{v}$ zdravstvu na podiplomskih izobraževanjih pridobljene sposobnosti za upravljanje in

Monika Ažman, dipl. m. s.; predsednica Zbornice zdravstvene in babiške nege - Zveze slovenskih društev medicinskih sester in zdravstvenih tehnikov Slovenije, Ob železnici 30 a, 1000 Ljubljana, Slovenija 
vodenje ter znanja in kompetence za naslednja področja: komunikacija in gradnja odnosov, znanje o zdravstvu in okolju, sodobni pristopi $\mathrm{v}$ vodenju, izgradnja profesionalizma na vseh ravneh, učinkovito upravljanje sistema, razvoj znanj in sposobnosti pri zaposlenih za ustrezen odziv na potrebe okolja, demografski trendi, javnozdravstveni problemi, izgradnja vrednot, ki podpirajo $\mathrm{z}$ dokazi podprto delo, odgovornost, kakovost in varnost, medsektorsko povezovanje, udejanjanje politike nenehnega spremljanja in izboljševanja kakovosti ter udejanjanje načel kakovosti, uvajanje informacijske tehnologije $\mathrm{v}$ zdravstvu tudi $\mathrm{z}$ vidika izboljševanja procesov dela in aktivne vključenosti uporabnikov storitev (American College of Healthcare Executives, 2014 cited in Skela-Savič, 2017; Skela-Savič, 2016b cited in Skela-Savič, 2017). Znanje managementa pa ni edina resna ovira za premik $\mathrm{v}$ pravo smer. Morda največji izziv v tem trenutku, ne le za management zdravstvene nege, temveč za celotno slovensko družbo, predstavlja pomanjkanje kadra $\mathrm{v}$ zdravstveni negi. Slovenska kategorizacija zahtevnosti bolnišnične zdravstvene nege, ki se izvaja od leta 1997 najprej v okviru raziskovalnega projekta, od decembra 2004 pa v okviru Razširjenega strokovnega kolegija za zdravstveno nego pri Ministrstvu za zdravje Republike Slovenije (SKZBZN) kot najvišjega svetovalnega organa na področju zdravstvene nege, je zanesljivo orodje, primerljivo tudi $\mathrm{z}$ mednarodnim okoljem. $\mathrm{Za}$ vse izvajalce enotno določa protokol izvajanja, nadzora in zbiranja ter analize podatkov kategorizacije, ki temelji na potrebah pacientov. Analiza podatkov SKZBZN kaže, da pomanjkanje kadra v zdravstveni negi beležimo že od leta 2007, ko je bilo pomanjkanje izvajalcev zdravstvene nege 21,46-odstotno. Analiza podatkov med letoma 2008 in 2013 kaže, da v Sloveniji manjka že 21,78 odstotka izvajalcev zdravstvene nege. Podatki za leto 2014 izkazujejo 23,90-odstotno pomanjkanje izvajalcev zdravstvene nege - tako diplomiranih medicinskih sester kot tehnikov zdravstvene nege. $\mathrm{V}$ letu 2015 je bil ta primanjkljaj, kot izhaja iz podatkov SKZBZN, 24,90-odstoten, leta 2016 pa že 25,40-odstoten (Zbornica - Zveza, 2018). Desetletno opozarjanje na preobremenjenost zaposlenih $\mathrm{v}$ zdravstveni negi ni obrodilo večjih sadov. Bregar in Skela Savič (2013) opozarjata, da pri oblikovanju politike zdravstvenega sistema strokovna stališča zaposlenih $\mathrm{v}$ zdravstveni negi niso upoštevana, čeprav bi $\mathrm{z}$ njihovim sodelovanjem verjetno povečali možnosti za razvoj pravičnega, solidarnega, univerzalnega in učinkovitega sistema zdravstvenega varstva. Zaposleni v zdravstveni negi si želijo in si prizadevajo za pomembnejšo vlogo pri oblikovanju politike zdravstvenega sistema. Znotraj zdravstvenega sistema sodijo med bolj motivirane za spremembe.

Vizija informatizacije zdravstvene nege je razvoj uporabnikom prijazne in sodobne informacijske podpore vsem procesom $\mathrm{v}$ zdravstveni negi in oskrbi. Informatizacija zdravstvene nege in oskrbe se razvija in deluje skladno z nacionalno strategijo e-zdravje (Kodele, 2010 cited in Kadivec, et al., 2013). Enotna uvedba e-recepta in e-napotnice je edino, kar smo v zadnjih desetih letih uspeli doseči na področju informatizacije v slovenskem zdravstvu nasploh. Kdo ve koliko časa, predvsem pa volje bo še potrebno, da bo na ravni države možno enotno spremljanje podatkov za posameznika / pacienta ne glede na to, ali je obravnavan na primarnem, sekundarnem ali terciarnem nivoju. Prav zaradi te nepovezanosti se tudi izvajalci zdravstvene nege izgubljajo $\mathrm{v}$ množici administrativnih obremenitev, ki se velikokrat podvajajo, najprej v pisni in nato še $\mathrm{v}$ e-obliki. Zdravstvena nega še ni enakovredno vključena $v$ področje e-zdravja.

Zbornica zdravstvene in babiške nege - Zveza strokovnih društev medicinskih sester, babic in zdravstvenih tehnikov Slovenije (Zbornica - Zveza) je izdala prvo tiskano verzijo knjige Negovalne diagnoze NANDA- I: definicije in klasifikacija 2015-2017. Poleg tega se prevaja verzija 2018-2020, katere e-licenca bo pomembna osnova za vzpostavitev pogojev, da se zdravstvena nega enakovredno vključi v e-zdravje.

Stanje na področju pravnega reda je za poklicno skupino zaposlenih $\mathrm{v}$ zdravstveni negi in oskrbi $\mathrm{v}$ naslednjem obdobju treba izboljšati. Tako bodo doseženi cilji, ki bodo dejavnost zdravstvene nege in oskrbe normirali na način, da bodo zaposleni v zdravstveni negi in oskrbi lahko na vseh ravneh zdravstvene dejavnosti opravljali svoje poslanstvo v pravnih okvirih, ki jim bodo nudili kar največjo stopnjo varnosti in tudi ustrezno mero avtonomnosti, uporabnikom zdravstvenih storitev pa največjo možno kakovost in varnost storitev zdravstvene nege in oskrbe (Kadivec, et al., 2013). Zakon o dejavnosti zdravstvene in babiške nege ter oskrbe je s strani strokovne organizacije Zbornice - Zveze pripravljen že dlje časa. Glede na politično nezainteresiranost za začetek postopka sprejema zakona je Zbornica - Zveza skupaj z Ministrstvom za zdravje in sindikati, ki vključujejo izvajalce zdravstvene, babiške nege in oskrbe, intenzivno sodelovala pri pripravi sistemskih rešitev, zapisanih v Noveli Zakona o zdravstveni dejavnosti (ZZDej-K), sprejeti 19. septembra 2017. Njen 38. člen rešuje vprašanje negotovosti in statusa izvajalcev s srednjo strokovno izobrazbo, saj ob vstopu Republike Slovenije v EU v letu 2004 in prevzemu Direktive 2005/36/ES o priznavanju poklicnih kvalifikacij v slovenski pravni red ni bilo ustrezno rešeno (Direktiva Evropskega Parlamenta in Sveta 2005/36/, 2005).

Novela ZZDej-K predvideva, da Razširjeni strokovni kolegij za zdravstveno nego v sodelovanju z Zbornico - Zvezo in s soglasjem ministrstva, pristojnega za zdravje, sprejme dokument prenovljene poklicne aktivnosti in kompetence $\mathrm{v}$ zdravstveni negi. Minister za zdravje Aleš Šabeder je k omenjenemu dokumentu z naslovom Poklicne kompetence in aktivnosti izvajalcev $v$ dejavnosti zdravstvene nege podal soglasje 16. maja 2019 , več kot leto dni po zakonsko določenem roku. 
Pri nadaljnjem urejanju področja bosta izjemno odgovornost nosila vodstvo zdravstvenih zavodov in management zdravstvene nege, saj predlog novele ZZDej-K predvideva, da izvajalci zdravstvene dejavnostivaktih o sistemizaciji delovnih mest določijo nova delovna mesta diplomiranih medicinskih sester in delovna mesta tehnikov zdravstvene nege. Kako uspešni bodo, bo pokazal čas.

Vizija razvoja dejavnosti zdravstvene nege in oskrbe, zapisana v Strategiji razvoja zdravstvene nege in oskrbe $v$ sistemu zdravstvenega varstva $v$ Republiki Sloveniji za obdobje od 2011 do 2020 (2011) opredeljuje, da bodo izvajalci zdravstvene nege nenehno nadgrajevali svoje znanje in razvijali na dokazih temelječo zdravstveno nego in oskrbo. $\mathrm{Z}$ vključevanjem $\mathrm{v}$ interdisciplinarne time bodo pomemben člen celostne obravnave pacienta in bodo sposobni izvajati zdravstveno nego in oskrbo na osnovi poklicnih aktivnosti in kompetenc ter na osnovi lastnih strokovnih smernic, standardov, priporočil, navodil in kliničnih poti. Zares pomembno vlogo na tem področju ima strokovna organizacija Zbornica - Zveza, ki ji je bilo leta 2005 s strani Ministrstva za zdravje prvič podeljeno javno pooblastilo za regulacijo lastne stroke. Prvič je bilo javno pooblastilo podeljeno za tri leta, zadnje pa že za obdobje sedmih let, in sicer od 2016 do 2023. Javno pooblastilo opredeljuje: vodenje registra izvajalcev zdravstvene in babiške nege, izdajanje, podaljševanje in odvzem licence izvajalcem zdravstvene in babiške nege, izvajanje strokovnega nadzora $s$ svetovanjem, načrtovanje specializacij in specialističnih izpitov. Omenjeno pooblastilo regulatorju poklica (Zbornici - Zvezi) nalaga pristojnosti, da bedi nad vseživljenjskim izobraževanjem izvajalcev zdravstvene in babiške nege ter oskrbe, prav tako pa od regulatorjev zahteva razvoj specialističnih področij $\mathrm{v}$ zdravstveni negi. Tako je Zbornica - Zveza že opredelila šest področij in pripravila okvir izvedbe kliničnih specializacij za: obravnavo in vodenje pacienta s kronično nenalezljivo boleznijo, specializacijo s področja urgentnih stanj, specializacijo s področja duševnega zdravja, psihiatrije in nevrologije, specializacijo $s$ področja zdravstvene nege in oskrbe pacienta s stomo, kronično rano in inkontinenco (enterostomalne terapije), specializacijo $s$ področja zdravstvene nege $\mathrm{v}$ onkologiji in hematologiji ter predlog in strokovno utemeljitev specializacije $s$ področja zdravstvene nege na domu in $\mathrm{v}$ lokalni skupnosti.

Zbornica - Zveza je v letu 2017 prvič pripravila lastno strategijo razvoja organizacije za obdobje 2017-2022, v kateri je med drugim zapisano, da se zdravstvena in babiška nega v svetu in Sloveniji razvija $\mathrm{v}$ kompleksno, na dokazih podprto ter $\mathrm{k}$ pacientu in celostni obravnavi osredotočeno stroko. Zaradi spreminjajočih se zdravstvenih potreb prebivalstva, vedno starejše populacije in vedno krajše zdravstvene obravnave $\mathrm{v}$ bolnišnicah medicinske sestre, babice in tehniki zdravstvene nege izzive, ki jih sodobna družba zahteva od njih, izpolnjujejo s predanostjo, strokovnostjo in znanjem.

Hitremu razvoju in nenehnim spremembam se mora prilagajati tudi Zbornica - Zveza kot enovito strokovno in reprezentativno telo izvajalcev zdravstvene in babiške nege. Čeprav s ponosom gradimo na naši častitljivi, že več kot devetdesetletni zgodovini ter izjemnih dosežkih naših predhodnic in predhodnikov, smo danes bolj kot kdaj koli prej soočeni $\mathrm{z}$ vprašanjem, kako $\mathrm{v}$ razmerah, ki nam pogosto niso najbolj naklonjene, narediti nove korake $\mathrm{k}$ izboljšanju položaja svojih članic in članov, stroke in same stanovske organizacije. Delujemo v okolju, kjer se od nas vsepovsod pričakuje in zahteva več: več pričakujejo članice in člani, več pričakujejo pacienti, njihovi bližnji in družba kot celota.

Hkrati bolj kot kdaj koli prej naš svet oziroma njegovo dojemanje krojijo množični mediji, vključno s spletnimi. Naš uspeh in položaj tako nista odvisna samo od tega, ali smo nekaj naredili dobro, odlično ali celo izjemno, temveč - in to velja tako v dobrem kot slabem - tudi od tega, če so to opazili in ustrezno prepoznali drugi. To je sodobno okolje, ki pomembno kroji vse naše uspehe, pa naj si gre za dogovarjanje s pristojnimi državnimi institucijami ali povezovanje $\mathrm{z}$ drugimi poklicnimi skupinami $\mathrm{v}$ zdravstvenem sistemu in izven njega (Strategija Zbornice - Zveze za obdobje 2017-2022 z akcijskim načrtom, 2017).

Izzivov za prihodnost tako strokovne organizacije Zbornice - Zveze, stroke zdravstvene in babiške nege kot izvajalce same zagotovo ne bo zmanjkalo. Visoko pomanjkanje izvajalcev zdravstvene nege, ki smo mu priča $\mathrm{v}$ današnjem času, vpliva na kakovost zdravstvenih storitev in na varnost pacientov ter posledično na slabše izide zdravstvene obravnave. Povečanje potreb po dodatnem kadru $\mathrm{v}$ zdravstveni negi izhaja iz povečanih potreb pacientov in povečane zahtevnosti zdravstvene nege. Poleg tega zaposleni v zdravstveni negi delajo po zastarelih standardih in normativih iz leta 1984, ki jih je treba nujno posodobiti.

Triletna globalna kampanja »Nursing Now « (20182020), ki poteka pod okriljem Svetovne zdravstvene organizacije in Mednarodnega sveta medicinskih sester, nosi pomembno sporočilo o izboljšanju statusa in položaja medicinskih sester in babic po vsem svetu. V kampanjo se je vključila tudi Zbornica - Zveza kot nacionalna strokovna organizacija pod imenom »Nursing Now Slovenija«. S tem tudi slovenske medicinske sestre in babice sporočajo, da želijo zasesti svoje mesto $\mathrm{v}$ središču reševanja zdravstvenih izzivov 21. stoletja (Skela Savič, 2019).

Po sto letih delovanja medicinskih sester na Slovenskem verjamemo, da je napočil čas, da oba regulirana poklica dobita samostojno zakonsko osnovo in se tako vzporejata $\mathrm{z}$ drugimi tremi reguliranimi poklici $\mathrm{v}$ zdravstvu. Vlada skupaj s parlamentom oblikuje politiko in strategijo države. Več vlad preteklega desetletja je zdravstvo postavilo kot prioriteto, tudi 
aktualna, zato je skrajni čas, da se zdravstveno in babiško nego umesti v zdravstveno varstvo na mesto, ki ji pripada tako $\mathrm{v}$ dobrobit pacientov kot izvajalcev.

\section{Literatura}

Bregar, B., \& Skela-Savič, B., 2013. Pomen vključevanja zaposlenih $\mathrm{v}$ zdravstveni negi pri oblikovanju politike zdravstvenega sistema. Obzornik zdravstvene nege, 47(1), pp 18-27. Available at: http://www.obzornikzdravstvenenege.si/2013.47.1.18 [6. 6. 2019].

Direktiva Evropskega parlamenta in Sveta 2005/36/, 2005. Uradni list Evropske unije L 255/22.

Gradišek, A., 1970. Petdeset let dela in oblikovanja medicinske sestre na Slovenskem: govor na jubilejni skupščini ZDMSS v Ljubljani dne 5. decembra 1969. Obzornik zdravstvene nege, 4(1), pp 8-31. Available at: http://www.obzornikzdravstvenenege.si/1970.4.1.8 [6. 6. 2019].

Kadivec, S., Skela-Savič, B., Kramar, Z., Zavrl-Džananović, D., \& Bregar, B., 2013. Strategija razvoja zdravstvene nege in oskrbe v sistemu zdravstvenega varstva v republiki Sloveniji za obdobje od 2011 do 2020: povzetek. Obzornik zdravstvene nege, 47(1), pp. 97-112. Available at: http://www.obzornikzdravstvenenege.si/2013.47.1.97 [6. 6. 2019].

Resolucija o nacionalnem planu zdravstvenega varstva 20162015, 2016. "Skupaj za družbo zdravja«. Uradni list Republike Slovenije št. 25. Available at: https://www.uradni-list.si/glasilo-uradni-list-rs/vsebina/201601-0999? sop=2016-01-0999 [8. 6. 2019].
Skela-Savič, B., 2017. Professionalization of nursing in Slovenia: challenges and responsibilities for nurses with a higher education degree. Obzornik zdravstvene nege, 51(4), pp. 264-273. https://doi.org/10.14528/snr.2017.51.4.202

Skela-Savič, B., 2019. Svetovna kampanja Nursing Now. Utrip, 22(5), pp. 22-24.

Strategija razvoja zdravstvene nege in oskrbe $v$ sistemu zdravstvenega varstva $v$ republiki Sloveniji za obdobje od 2011 do 2020, 2011. Ljubljana: Ministrstvo za zdravje. Avaliable at: http://www.zbornica-zveza.si/sites/default/files/doc attachments/strategija razvoja zn 2011-2020 okt 2011.pdf [8. 6. 2019].

Strategija Zbornice - Zveze za obdobje 2017-2022 z akcijskim načrtom, 2017. Ljubljana: Zbornica zdravstvene in babiške nege Slovenije - Zveza strokovnih društev medicinskih sester, babic in zdravstvenih tehnikov Slovenije Available at:

http://www.zbornica-zveza.si/sl/strategija-zbornice-zveze-zaobdobje-2017-2022-z-akcijskim-nacrtom-0 [9. 6. 2019].

Zbornica - Zveza, 2018. Verodostojni in primerljivi podatki $o$ pomanjkanju medicinskih sester. Ljubljana: Zbornica zdravstvene in babiške nege Slovenije - Zveza strokovnih društev medicinskih sester, babic in zdravstvenih tehnikov Slovenije. Available at:

http://www.zbornica-zveza.si/sl/verodostojni-primerljivipodatki-o-pomanjkanju-medicinskih-sester [8. 6. 2019].

Citirajte kot / Cite as:

Ažman, M., 2019. Utrinek časa ob stoletnici poklica medicinske sestre na Slovenskem. Obzornik zdravstvene nege, 53(2), pp. 100-103. https://doi.org/10.14528/snr.2019.53.2.2978 